\title{
Integrating and Utilizing AHP and GIS for Landfill Site Selection
}

\author{
Mohd Zulkifli Mohd Yunus ${ }^{1, a^{*}}$,Izni Izzati Mohamad ${ }^{1, b}$, \\ Chek Maslinda Omar ${ }^{1, c}$, Mohd Badruddin Mohd Yusof ${ }^{1, d}$ \\ ${ }^{1}$ Faculty of Civil Engineering, Universiti Teknologi Malaysia, 81300 Skudai, Johor, Malaysia \\ amzul@utmspace.edu.my, bezne007@gmail.com, ${ }^{\mathrm{c}} \mathrm{cmaslindaomar@gmail.com,}$ \\ and ${ }^{\mathrm{d}}$ mbadruddin@utm.my
}

Keywords: AHP, GIS, landfill, site selection.

\begin{abstract}
Landfill site selection is a complex task that needs to be done by decision maker. There are many criteria that need to be considered before choosing the landfill. This includes economic, social, geological and environmental criteria. AHP is a technique for analyzing and supporting decisions in which multiple and competing objectives are involved and multiple alternatives are available. By using Analytical Hierarchical Process (AHP), the process of landfill site selection had become easier. In this method, the problem need to be divided into hierarchy before the pair wise comparison and made it prioritize accordingly. Then, the judgment will be synthesized and finally, the evaluation and consistency of judgment were checked. As a result, lists of criterion were arranged according to its priority, which is more dominant to economic aspect and less dominant to social aspect. This is on account of social matters can be solved alternatively by different systems. This landfill site selection process involved lots of spatial data and strenuous in handling it. Thus, by using GIS, it can give significant helps to solve this issue because of its potential in handling large volume of spatial data that needs to be evaluates and processed. This particular research used Johor Bahru, Johor for case study area.
\end{abstract}

\section{Introduction}

Landfill is one of the approaches used in waste management. Other approaches include composting and incineration but the oldest and most common method used is landfill since it is more convenient and cheaper compared to other methods. However, this option has caused lots of problem in waste management sector. It is because; Malaysia population has increased over years which give impact to the increasing level of waste produced. In Malaysia, the average solid waste disposed from January to March 2010 is 20,500 tonned per day and in Johor; the amount solid waste disposed is 2,600 tonne per day [1]. This increased has caused congestion at the landfill and make its lifespan shorter than expected. Even though Malaysia is among the most developed countries in Asian, the standard of its waste management is rather poor. Developed nations such as Denmark, Austria and Japan have efficient waste management system to deal with the waste generated by their citizens but similar scenarios are non-existent in transitory countries such as Malaysia [2].

Landfill is recommended and acceptable method of solid waste disposal. But, it's often misunderstanding with waste disposal in open and burning dumps. It is not open dump where salvage is permitted and usually exhibit undesirable characteristics of a dump: unsightly appearance, burning waste, blowing dust and paper, infestation by rodent, pollution of air and groundwater [3]. The life-cycle of landfill starting from planning phase, construction phase, operation phase, completed phase, and final storage phase [4].

In assessment and evaluation method of suitable landfill site, there are numbers of evaluation are used which are [5];

i. Ad hoc methods compare alternatives in narrative terms without using any explicitly stated method to order the preferences. These methods involve professional judgment, hard to explain to public and not likely to be accepted in today's environment. 
ii. Checklist methods compare and evaluate alternatives against a specified set of criteria with no compensatory rules or tradeoff.

iii. Economic methods- use economic procedures and principle to translate no commensurable units into monetary units.

iv. Cartographic methods- compare and evaluate alternatives sites using maps

v. Pair wise comparison methods use the sequential comparison alternatives in pairs as a basis for subsequent ordering of preferences.

vi. Matrix methods use a matrix for the summary, comparison, and evaluation of criteria and alternatives.

This paper aims to identify the parameters and criteria need to use for landfill site selection and its constraints factors; to apply AHP as a tools in decision making process; integrating the usage of Geographic Information System (GIS) in processing spatial data and lastly to proposed most optimal alternative for the future landfill site.

\section{Parameters in landfill site selection}

There are parameters that need to follow in landfill selection. The standard criteria used are as shown in Table 1.0. In the table, it shows that the new selected landfill must buffering $1000 \mathrm{~m}$ from residential, $100 \mathrm{~mm}$ from water bodies, $1000 \mathrm{~m}$ from groundwater sources, and $25 \mathrm{~km}$ from transfer station.

Table 1.0: Standard criteria for new landfill site selection (derived from A.Zubaidah [6])

\begin{tabular}{|c|l|c|}
\hline No. & Standard criteria for new landfill site selection & Malaysia specification \\
\hline 1 & Residential $(\mathrm{m})$ & 1000 \\
\hline 2 & Water bodies $(\mathrm{m})$ & 100 \\
\hline 3 & Groundwater line $(\mathrm{m})$ & 1000 \\
\hline 4 & Distance from transfer station $(\mathrm{km})$ & 25 \\
\hline 5 & Protected forest $(\mathrm{m})$ & 3000 \\
\hline 6 & Airport location $(\mathrm{m})$ & 3000 \\
\hline 7 & Road line $(\mathrm{m})$ & 500 \\
\hline 8 & Slope $(\%)$ & 10 \\
\hline 9 & Soil permeability $(\mathrm{cm} / \mathrm{sec})$ & $<10^{-6}$ \\
\hline 10 & Fault line $(\mathrm{m})$ & 100 \\
\hline
\end{tabular}

\section{Methodology}

\section{Analytical Hierarchical Process (AHP)}

AHP is one of the methods in Multiple Criteria Decision Analysis (MCDA). It is based on three principle which are; decomposition, comparative judgment, and synthesize of priorities. From these principles, there are three steps in AHP. The steps are:

1. Develop the AHP hierarchy as shown in Figure 1

2. Compare the decision elements on pair-wise base

3. Construct an overall priority rating

\section{a. Development of AHP hierarchy}

The first step in AHP is to construct the hierarchy according to the problem. The hierarchical consist of 4 levels which are: focus, criteria, sub-criteria and alternatives; which in this research presented in GIS database. The hierarchical structure of landfill site selection is as shown in Figure 1. The main focus is to site the new landfill site. The criteria divided into 4 which are geographical factor, economic factor, environmental factors and social factors. The sums of all sub criteria from these 4 criteria are 15 sub criteria. 


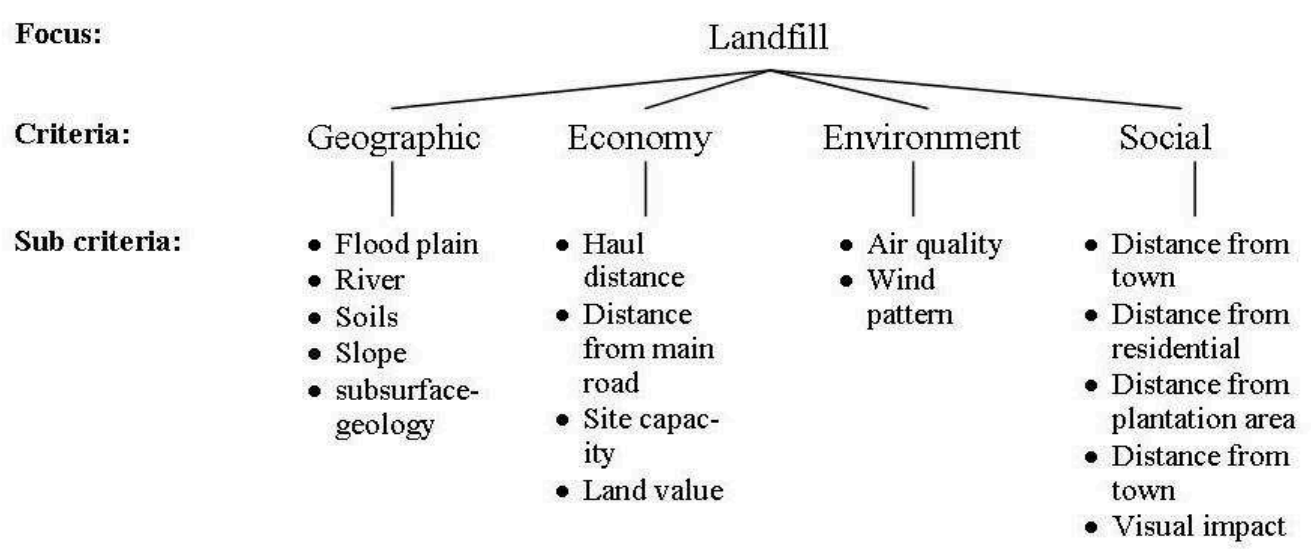

Figure 1: Hierarchical structure of landfill site selection (derived from P.Cabala[7]).

\section{b. Compare the decision elements on pair wise base}

In pair wise comparison, there are 3 steps which are; 1) develop the pair wise comparison matrix; 2) computing the criterion weight by summing all values in each column in the matrix, divided the elements in matrix by its column total and calculate the average of the elements in each rows of the normalized matrix; 3 ) determine the consistency of the ratio after calculating the second step. The ratio less than 0.10 is considered consistent but if the ratio are more than 0.10 , the original values in pair-wise comparison matrix should be revised because it indicates inconsistencies in the judgments [9].

The scale used in the matrix are range from 1-9. This scale is used when the elements to be analyzed for all elements are not possible. Thus, by using this scale, it will allow analyst to determine their preferences between the sets of combined elements [5]. The scale used as shown in Table 2. The odd numbers; $1,3,5,7,9$ are used but if there any doubts in the preferences, even numbers are used.

Table 2: Scale used for evaluation in pair wise comparisons [8]

\begin{tabular}{|c|c|}
\hline Intensity of importance & Definition \\
\hline 1 & Equal important \\
\hline 3 & Moderate important \\
\hline 5 & Strong importance \\
\hline 7 & Very strong importance \\
\hline 9 & Extreme importance \\
\hline $2,4,6,8$ & For compromise between the above values \\
\hline
\end{tabular}

\section{c. Construct an overall priority rating}

The aggregation of the relative weight of levels obtained in pair wise matrix is the final steps in weighting analysis. In this step, the means of a sequence of multiplication of relatives weights at each level of hierarchy are calculate. All necessary calculations can be perform by computer program such as Expert Choice and by using templates prepared by SCB Associates Ltd [10].

In this research, 100 sets of questionnaire had been distributed to the local authorities to get their opinion on their expertise of waste management. Their opinion then converted to a weightage which had been used in analyzing the AHP.

\section{Finding and discussion}

Table 3 shows the results of the analysis done for the AHP. As in the table, it shows that the main factors need to be consider in landfill selection is distance from river or aquifer, distance from town and land value of selected site which each of them are $13.3 \%, 10.9 \%$ and $10.4 \%$ respectively. 
The least important criteria to consider are potential visual impact to the public only $3.2 \%$. The consistency ratio of the index is 0.09 , lower than 0.10 . This indicates the judgments of the criteria are consistent and no re-evaluation needed.

Table 3: Overall priority rating

\begin{tabular}{|c|c|c|c|}
\hline & \multicolumn{2}{|c|}{ AHP } & Consistency check \\
\hline 1 & 0.045 & $4.5 \%$ & \multirow{2}{*}{$\begin{array}{c}\text { Consistency OK } \\
9 \%\end{array}$} \\
\hline 2 & 0.109 & $10.9 \%$ & \\
\hline 3 & 0.072 & $7.2 \%$ & \\
\hline 4 & 0.040 & $4.0 \%$ & \\
\hline 5 & 0.071 & $7.1 \%$ & \\
\hline 6 & 0.066 & $6.6 \%$ & \\
\hline 7 & 0.066 & $6.6 \%$ & \\
\hline 8 & 0.045 & $4.5 \%$ & \\
\hline 9 & 0.032 & $3.2 \%$ & \\
\hline LO & 0.133 & $13.3 \%$ & \\
\hline L1 & 0.080 & $8.0 \%$ & \\
\hline 12 & 0.046 & $4.6 \%$ & \\
\hline L3 & 0.052 & $5.2 \%$ & \\
\hline L4 & 0.040 & $4.0 \%$ & \\
\hline L5 & 0.104 & $10.4 \%$ & \\
\hline
\end{tabular}

The results achieved shows that the landfill selected must be in safe buffering zone from river because the river could easily contaminated by the landfill waste such as leachate and will cause many problems to the water resources. Distance from town are important because if the landfill are near to the town, it will distract all activities in town because of the bad smell from the landfill and the land value is important because the landfill is a nonprofit and non commercial business. So, to reduce the cost, the cheaper land value should be selected as new landfill site. The potential visual impact become least important criteria because, the visual issues can be manage by build high wall around the landfill.

\section{Utilization of GIS}

GIS consist of software, hardware, people and data. The four types of hardware related to GIS are; data collection device, data input device, data storage devices and analysis software, and data output services. There are two ways of data collection; using observations process and existing maps. The main key of data collection is not only captures attributes information but also collect accurate information on the location of each measurement of that attribute.

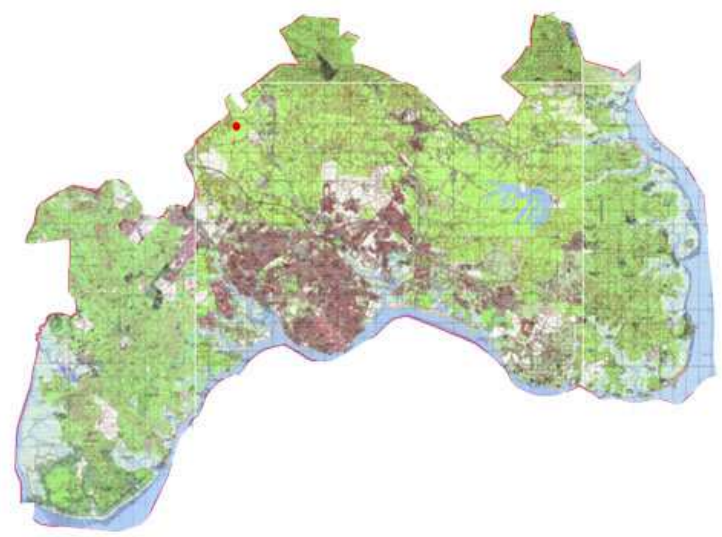

Figure 2: New landfill sites are shown in red dot.

Geological use of GIS have been explore and being exploited beyond measure because its ability to bring together the result of conventional field mapping, satellite-based interpretations of geological structure, multi-sources geographical data and the results of regional geochemical 
surveys [11]. Even though there are still lack of GIS potential because often associated not more than automated map editing system, it's have obvious relevance to research world, not only for storage and display the data, but also its ability to bring together data sets for better data extraction and integration. In this research, GIS are use to combined all data needed since its involved lots of maps. The maps of new landfill site are shown in Figure 2. By using GIS and AHP, all these maps can be manage and process to select new landfill site more efficiently.

\section{Conclusion}

In landfill site selection, there are many parameters and factors need to take accounts before the selection are done. The customary technique couldn't generally assess all the constraints simultaneously at the same time and parameters maps are changing quickly overtime makes the reproduction limited. The integration of GIS and AHP helps to produce credible analyses and works as an alternatives for customary technique for landfill site selection. Likewise, it will permit to apply analysis allowing having the most applicable and beneficial at spatial temporal scale. This integration can helps developers and planners to determined suitable landfill site in the future.

\section{Acknowledgement}

The authors appreciate the financial support for this work from Universiti Teknologi Malaysia, Ministry of Education Malaysia, VOT No. (10J01).

\section{References}

[1] National Solid Waste Management Department of Malaysia (2010). Retrieved from http://www.kpkt.gov.my

[2] Agumuthu and Fauziah. Challenge and issues in moving towards sustainable landfilling in a transitory country-Malaysia, J. Waste Management \& Research. 2011. 29(1):13-19.

[3] Kirov, N. Y. Principles of waste management- unit operations and process. Sydney: Kingsway Printers Pty. Ltd, 1975.

[4] Christensen, T. H. Environmental Aspects of sanitary landfilling. In T. H. Christensen, R. Cossu, \& R. Stegmann, Sanitary landfilling: process, technology and environmental impact, Denmark: Academic Press, 1989, pp. 19-25.

[5] McBean, E. A., Rovers, F. A., and Farquhar, G. J. Solid waste landfill engineering and design. New Jersey: Prentice Hall, Inc., 1995.

[6] Siti Zubaidah Binti Ahmad. Application of GIS In Extracting Spatial Criteria From Existing Landfill Site; A Study on Pulau Burung Landfill Site.(n.d) Universiti Sains Malaysia

[7] Pawel Cabala. Using the analytical hierarchy process in evaluating decision alternatives. J. Operations Research and Decisions, 2000.

[8] Saaty, T., The Analytic Hierarchy Process, Mc.Graw-Hill, New York, 1980.

[9] J. Malczewski, GIS and Multicriteria Decision Analysis. John Wiley \& Sons Inc., Canada, 1999.

[10]www.scbuk.com. SCB Associates. AHP Template.

[11] Knill, J. Geographical Information Systems: the environmental view'. In book: Geographical Information Handling-Research and Applications. Paul Mather (ed.), John Wiley and Sons, Chichester, UK, 1993, pp. 7-15. 